\title{
EL FACTOR TUBARIO EN LA ESTERILIDAD FEMENINA
}

\author{
Dr. Bernardo Botero Peláez* \\ Dr. Oscar Acebedo Ferrer** \\ Dr. Jesús Montes Sáenz***
}

SOCIEDAD CALDENSE DE OBSTETRICIA Y GINECOLOGIA

\section{Prólogo}

En la ciudad de Manizales antes del año de 1943, la ginecología era una rama quirúrgica ejercida por médi$\cos$ y cirujanos generales. Se asistía entonces a los albores de la hormonoterapia y la fisiología del aparato reproductor era mal conocida.

En el año de 1943, establecimos en el viejo Hospital Municipal de Manizales una consulta ginecológica e iniciamos la conformación del Servicio de Ginecología, disperso hasta entonces. Simultáneamente, iniciamos el estudio del matrimonio estéril provistos de unas cánulas metálicas de origen alemán y una pera de goma, con las cuales pretendíamos explorar la función tubaria; por fortuna no tuvimos accidentes que lamentar al persuflar aire, pero sí algunos éxitos.

Animados con nuestras primeras experiencias y conociendo los avances obtenidos en otros medios, consignados en la literatura americana, mexicana y argentina, mejoramos nuestra información y la manera de conducir la investigación de los factores de esterilidad. Adquirimos equipo más adecuado y establecimos historia clínica y archivo apropiados. La Histerosalpingografía empezó a practicarse en nuestro medio por el año de 1949.

Por la misma época iniciamos algún estudio del varón con la ayuda de los urólogos, reticentes en ese entonces, pues no querían adentrarse en el estudio de la andrología, fenómeno que se presentaba en el mundo entero.

La asistencia al Primer Congreso Mundial de la IFA celebrado en New York en el año de 1953, marcó para nosotros, como para la mayoría de los médicos asistentes, una etapa de progreso en estas disciplinas.

Posteriormente, tuvimos la grata experiencia de recibir enseñanzas directas de precursores como Normando Arenas, Edmundo G. Murray,

* Profesor Asistente del Departamento de Ginecología y Obstetricia. Facultad de Medicina. Universidad de Caldas.

** Profesor Asistente y Jefe del Departamento de Ginecología y Obstetricia. Facultad de Medicina. Universidad de Caldas.

*** Profesor Asistente y Jefe de la Unidad Ginecológica del Departamento de Ginecología y Obstetricia. Facultad de Medicina. Universidad de Caldas. 
Bettinotti Di Paola, Lelio, Uzubiaga, etc. Respecto a los factores masculinos de esterilidad tuvimos la oportunidad de recibir enseñanzas valiosas de Armando Trabuco. En el año de 1956 completamos nuestra motivación con la asistencia al Segundo Congreso Mundial de la IFA, en donde pudimos observar los grandes adelantos alcanzados en el campo de la esterilidad conyugal en los tres años anteriores.

En el año de 1957 se inició en el Hospital Universitario de Caldas una etapa superior en el estudio de la esterilidad conyugal, al fundarse la Cátedra de Ginecología, en donde hemos contado con la colaboración de distinguidos especialistas y en donde a partir de entonces reciben entrenamiento estudiantes, internos y residentes, constituyendo en nuestro medio parte integral de su formación como especialistas en Ginecobstetricia.

Cabe anotar que el elemento humano que asiste a las consultas privadas y hospitalarias de caridad es diferente $y$ no comparable en muchos aspectos; ésto sumado a las modalidades específicas del trabajo hospitalario, nos ha decidido a presentar a ustedes una casuística de la consulta privada, reservándonos para un informe posterior las experiencias recogidas en la consulta hospitalaria en el mismo lapso.

Para iniciar el estudio de la pareja estéril, acostumbramos ilustrar a los cónyuges sobre los procedimientos diagnósticos que se emplearán, la finalidad de cada uno de ellos y el tiempo aproximado para llevarlos a cabo. Este preámbulo, así como la enseñanza más elemental de la fisiología de la reproducción y sus posibles obstáculos, nos ha dado excelen- tes resultados para motivar a los cónyuges y obtener mejor colaboración.

Al llegar al consultorio de esterilidad, muchas parejas se sienten defraudadas y pesimistas, pues han sido sometidas a tratamientos empíricos hasta el punto de que es común entre nosotros el hecho de que después de haber sido sometida una mujer a un examen ginecológico, se le ha manifestado que es absolutamente normal y su esterilidad inexplicable lo cual, al darle una falsa sensación de seguridad, le hace perder tiempo precioso para recibir tratamiento adecuado.

A pesar de lo dicho y del interés que se toma para que el matrimonio colabore la "inconstancia de los cónyuges" continúa siendo el factor más importante de esterilidad. Esperan que desde la primera visita se les informe sobre las causas y que el tratamiento se inicie de inmediato.

Otro factor de influencia en nuestro medio lo constituye el estado socioeconómico, el cual limita el uso de ciertos procedimientos. Por otra parte, encontramos con frecuencia incumplimiento de algunas parejas que viven en sitios alejados de la ciudad.

Una de las barreras más difíciles de vencer la constituyen los maridos, pues no quieren ser tildados de "culpables" y siempre tratan de implicar a sus esposas. Tan importante es este aspecto, que muchas de nuestras historias están incompletas por esta causa, debiéndonos resignar frecuentemente con la prueba de Hühner como único medio de evaluar la capacidad fecundante del esposo, por imposibilidad de practicarle espermograma. 


\section{Metodología}

Si no se sigue un método en el estudio de la pareja estéril, no es posible tener éxito en muchos casos y en otros no podrá conocerse la causa reversible o irreversible de la esterilidad.

Tomamos de SIMONS (29), con algunas adaptaciones necesarias en nuestro medio, los procedimientos mínimos que se deben llevar a cabo tanto en el hombre como en la mujer.

\section{En la mujer:}

1. Historia y examen físico.

2. Análisis de laboratorio: Cuadro Hemático, Eritrosedimentación, Serología, Factor Rh, grupo sanguíneo, orina $\mathrm{y}$ heces.

3. Metabolismo basal, Yodoproteinemia.

4. Prueba de Rubin (persuflación quimográfica); Histerosalpingografía. trio.

5. Legrado y/o Biopsia de Endome-

6. Prueba de Hühner; Frotis cervical; estudio del Moco cervical, cristalización; Colpocitología, etc.

7. Temperatura basal.

\section{En el hombre:}

1. Historia y examen físico.

2. Análisis de laboratorio.

3. Metabolismo basal, Yodoproteinemia.

4. Examen del semen con datos mínimos: volumen, viscosidad, número de espermatozoides por cc.; móviles activos, móviles in situ, muertos, anómalos; estudio del sedi- mento para buscar piocitos, bacterias y sangre.

En la mujer son procedimientos condicionales: Neumopelvigrafía y Ginecografía, estudios hormonales, Nefroaerograma, Cultivo y Antibiograma de secreciones cervicales, Cultivo de Enciometrio, Estudios Sicológicos, etc.

En el hombre son procedimientos condicionales: Biopsia de testículo, Endoscopias y Estudios hormonales.

Debe hacerse énfasis en la elaboración cuidadosa de la historia clínica, teniendo en cuenta los antecedentes de TBC. personales y familiares, datos que hemos encontrado de importancia en relación con la esterilidad en nuestro medio (7).

Serán consignados además cuidadosamente los datos referentes a la menstruación, relaciones sexuales, líbido y orgasmo, frecuencia, dispareumia, etc. No es raro que nos encontremos con parejas que no tienen relaciones sexuales o son tan escasas como cada dos o tres meses, o excesivas, cuatro o cinco o más por día.

Como la ponencia que nos fue asignada para ser presentada a este Congreso se refiere al Factor Tubario en la Esterilidad Femenina, solo hemos querido mencionar muy rápidamente alguno sde los aspectos generales que consideramos de importancia en el estudio de la pareja estéril.

\section{FACTOR TUBARIO EN LA ESTERILIDAD (FT)}

El presente trabajo corresponde a las parejas estériles estudiadas por nosotros en la consulta privada en un lapso de 22 años (1945-1967). En este período de tiempo asistieron a la consulta de esterilidad 484 matri- 
monios estériles, de los cuales se investigó el FT en 322 mujeres. Las restantes fueron excluídas del presente estudio por diferentes razones: deserción, embarazo con motivo de las dilataciones cervicales y legrado; mejoría del estado del cérvix 0 el simple examen ginecológico (Factor sicológico), por lo cual no se llegó en ellas al estudio del FT. En consecuencia, los resultados que presentamos son depurados.

\section{Edad de las pacientes estudiadas}

Las mayores probabilidades de embarazo se tienen antes de los 30 años. Por encima de esta edad aparecen otros factores como miomatosis y endometriosis que alteran la cavidad uterina, la fisiología de las trompas, ovarios y peritoneo.

La edad de nuestras pacientes osciló entre los 18 y los 41 años. Menos de 20 años tenían 15 pacientes (4,6 por ciento); entre 20 y 29 años hubo 205 ( 63,7 por ciento); entre 30 y 3 9años (30,7 por ciento); de 40 y más años 3 pacientes $(0,9$ por ciento). En la Tabla 1 se presenta la distribución por edades.

TABLA 1

DISTRIBUCION DE 322 PACIENTES ESTERILES SEGUN GRUPOS DE EDADES

MANIZALES. 1945-1967

\begin{tabular}{lrr}
\hline Edad & \multicolumn{2}{c}{ Pacientes } \\
\hline Nenos 20 & 15 & $\%$ \\
$20-29$ & 205 & 4,7 \\
$30-39$ & 99 & 63,7 \\
40 y más & 3 & 30,7 \\
TOTAL & 322 & 0,9 \\
\hline
\end{tabular}

\section{Tipo de esterilidad}

Se considera como estéril primaria a la mujer que no ha concebido en el primer año de matrimonio. Las parejas que consultan por esterilidad durante el primer año de casadas no son tenidas en cuenta para estudio, siguiendo normas internacionales. Como esterilidad secundaria consideramos aquellos casos en los cuales no ha ocurrido embarazo dos años después del último parto 0 aborto. Solamente tratamos a las que no tienen un exceso de hijos. En la Tabla 2 se estudia la duración de la esterilidad en 322 pacientes.

TABLA 2

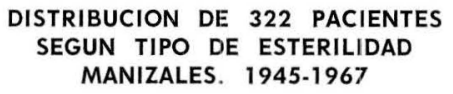

\begin{tabular}{lcc}
\hline & \multicolumn{2}{c}{ Pacientes } \\
Tipo & $\mathbf{N}^{\mathbf{0}}$ & $\%$ \\
\hline Primaria & 204 & 63,3 \\
Secundaria & 118 & 36,7 \\
\cline { 2 - 2 } TOTAL & 322 & $\overline{100,0}$ \\
\hline
\end{tabular}

\section{Investigación del factor tubario}

Para la investigación de FT se han utilizado diferentes métodos:

a) Prueba de Rubin o Persuflación Quimográfica (PQ).

b) Histerosalpingografía, complemento fundamental de la anterior.

c) Culdoscopia y Peritoneoscopia.

d) Prueba de Speck (Sulfofenolftaleína ).

e) Prueba del óleotransporte de Conill Serra.

f) Prueba del transporte de Radiosótopos de Stabile con Oro Radioactivo en estado colidal.

Para la investigación del FT hemos utilizado la Prueba de Rubin y la Histerosalpingografía. 


\section{Prueba de Rubin (PQ)}

Para practicar la prueba de Persuflación Quimográfica hemos utilizado los aparatos Kidde y Grafax.

\section{Interpretación de oscilaciones}

Consideramos permeabilidad normal, cuando en la gráfica de $P Q$ la línea asciende alrededor de $70 \mathrm{~mm}$. Hg. y registra de 4 a 7 oscilaciones por minuto con amplitud de 10 a 30 $\mathrm{mm}$. mientras dura la prueba (31).

Consideramos como estenosis aquellas gráficas en las cuales la línea asciende por encima de $100 \mathrm{~mm}$. Hg. pudiendo llegar a 150 o más, con oscilaciones o descenso en parábola. Algunas de estas gráficas pueden corresponder a espasmo.

Diagnosticamos oclusión tubaria cuando la línea asciende a $200 \mathrm{~mm}$. Hg. y continúa horizontal en platillo. En estos casos debe tenerse presente también la existencia de espasmo (17).

Dentro de estas tres gráficas que pudieran llamarse tipo, existen algunas modalidades de curvas condicionadas por diversos estados orgánicos - funcionales de las trompas.

El factor espasmo puede conducir a errores diagnósticos en la interpretación de PQ. Según Stallworthy (32), la oclusión funcional o espasmo es más frecuente que la oclusión orgánica uni 0 bilateral, sin previa cirugía. Por tal razón se ha recomendado el uso de drogas antiespasmódicas después de la primera $P Q$.

Para evitar el espasmo hasta donde sea posible, practicamos persuflación en los primeros días del ciclo, evitando el tiempo de ovulación ya que parece que en esta época es más frecuente el espasmo por estar aumentada la irritabilidad tubaria (22).
Con este mismo fin evitamos maniobras bruscas sobre el cérvix y esperamos que transcurran dos a tres minutos después de insertada la cánula para dar paso al gas.

Las complicaciones infecciosas se presentaron con extrema rareza en nuestras pacientes, lo cual atribuímos a la selección cuidadosa que hicimos de ellas. La ruptura de las trompas es un hecho excepcional si se evita sobrepasar la presión del gas por encima de $200 \mathrm{~mm}$. Hg. No reportamos ningún caso.

Después de terminada la $P Q$, generalmente se presenta un pequeño escurrimiento de sangre por la vagina, procedente del endometrio y del cérvix, el cual no requiere tratamiento.

\section{Fallas en la técnica}

Para evitar fallas en la técnica deben vigilarse los escapes en la fuente de $\mathrm{CO} 2$ o en el sistema, ya que daría la impresión de permeabilidad. La cánula no debe ser introducida muy profundamente para evitar la perforación del útero que daría falsa gráfica de permeabilidad o dificultad de la salida del gas por interferencia del endometrio, dando gráfica de estenosis u oclusión. La cánula debe ser purgada con el fin de asegurar su permeabilidad y expulsar el aire que contiene lo cual puede resultar peligroso, en vista de que la cantidad de aire que puede inyectarse accidentalmente en una $P Q$ varía entre los 5 y $25 \mathrm{cc}$. dependiendo de la longitud del sistema (36).

Mientras exista paso de gas, auscultamos el hipogastrio y las fosas ilíacas alternativamente con el objeto de escuchar el soplo tubario, el cual debe ser diferenciado del ruido que produce el gas al escaparse por el cérvix. Según Sweeney (36), no 
debe perderse el tiempo tratando de diferenciar calibres, estenosis o espasmos por los cambios de tono.

Finalmente no sobrepasamos los $100 \mathrm{cc}$. en cada prueba ni la prolongamos demasiado, pues resulta inútil llenar el abdomen con un exceso de gas, a menos que se quiera utilizar éste paar otros procedimientos diagnósticos. (neumopelvigrafía).

\section{Otros signos de interpretación}

Al terminar la $P Q$ y si se ha producido paso del gas a la cavidad peritoneal, encontraremos signos de neumoperitoneo y desaparición de la matidez hepática. Al incorporarse la paciente deberá sentir un dolor más o menos intenso, referido generalmente al hombro derecho (omalgia). Esta se explica por la presión que ejerce el gas al ascender al espacio subfrénico y por la vía del nervio frénico ocasionará el dolor reflejo. A veces el dolor es referido al epigastrio, al manubrio del esternón o a la escápula. Puede faltar en pacientes con trompas permeables, en las cuales el espacio subfrénico se encuentre bloqueado por procesos inflamatorios previos. En ausencia de omalgia consideramos la prueba negativa y la repetimos y complementamos con otros procedimientos.

La omalgia tardía es un signo muy importante porque sugiere la presencia de adherencias y bolsas que impiden la salida rápida del gas a la cavidad peritoneal. Puede demorar horas en aparecer dependiendo de la lentitud con la cual el gas escapa a la cavidad peritoneal; el médico debe ser informado por la paciente del tiempo de aparición. Colocando a la paciente en posición genupectoral o acostándola, el dolor cede temporalmente, disminuyendo a medida que el gas es eliminado por los pulmo- nes. La omalgia puede resultar intolerable y es necesario recurrir a los analgésicos.

La PQ ha sido empleada además para control durante la cirugía plástica de las trompas uterinas, durante el acto operatorio y después de él.

La repetición de la $P Q$ la empleamos frecuentemente para el tratamiento de las estenosis y oclusiones tubarias.

La $P Q$ está contraindicada en el embarazo, infecciones genitales activas, TBC genital (relativa), hemorragia presente y enfermedades generales como cardiopatías, hipertensión, diabetes, etc. No debe practicarse en el ciclo en el cual se llevó a cabo el legrado uterino.

El leucograma y la eritrosedimentación deben tenerse presentes previamente, lo mismo que el frotis cervical y si están alterados la paciente deberá ser sometida al tratamiento adecuado.

\section{Causas de oclusión tubaria}

El índice de oclusión tubaria ha variado entre cifras muy dispares, desde el 52 por ciento dado por Rubin en 1932 hasta el 5.25 por ciento reportado por Williams en 1955.

Las oclusiones tubarias en su gran mayoría son inflamatorias y el índice cambiará en cada región o país, de acuerdo con la incidencia de b!enorragia, aborto y parto sépticos.

Otras causas relativamente frecuentes de oclusión tubaria están constituidas por intervenciones quirúrgicas anteriores, maniobras intrauterinas bien $\circ$ mal conducidas.

Entre nosotros ha sido muy alto el índice de blenorragias complicadas 
tanto en el hombre como en la mujer. Muchas de nuestras pacientes, como lo indica su edad, corresponden a la época anterior a la quimio y antibioterapia, por lo cual presentan un alto índice de lesiones canaliculares.

De nuestro grupo de 322 pacientes a 302 se les practicaron $504 \mathrm{PQ}$ con un promedio de 1.6. Las PQ fluctuaron entre 1 y 7 por paciente. Las 20 restantes se investigaron por HSG exclusivamente.

Si analizamos el estado de las trompas a partir de la primera $P Q$, obtenemos los siguientes datos: Trompas permeables 159 (52.8 por ciento); trompas con estenosis 67 (22.1 por ciento) y ocluídas 76 (25.1 por ciento). Tabla 3 .

\section{TABLA 3}

\section{ESTADO DE LAS TROMPAS A LA PRIMERA PQ EN 302 MUJERES. \\ MANIZALES. 1945-1967}

\begin{tabular}{lcc}
\hline & \multicolumn{2}{c}{ Pacientes } \\
Estado & $\mathbf{N}^{\mathbf{0}}$ & $\%$ \\
\hline Permeables & 159 & 52,8 \\
Estenosis & 67 & 22,1 \\
Oclusión & 76 & 25,1 \\
\cline { 2 - 2 } TOTAL & 302 & 100,0 \\
\hline
\end{tabular}

\section{Histerosalpingografía (HSG)}

La HSG es un procedimiento de gran utilidad para la investigación del FT. Es un complemento de la PQ, superándola en muchos aspectos.

La indicación de HSG es selectiva en nuestra práctica. En primer lugar la hemos ejecutado en aquellas pacientes que presentan gráficas de $P Q$ persistentemente anormales sugiriendo espasmos, estenosis con o sin rigidez u oclusión franca. En segundo lugar la practicamos en aquellas pa- cientes en las cuales no encontramos otros factores de esterilidad después de un estudio completo, con el fin de buscar un factor peritoneal o una lesión de las trompas no sospechada.

Para practicar esta prueba descartamos sistemáticamente enfermedad pélvica inflamatoria aguda o reciente. Cuando existe fuerte sospecha de TBC genital, preferimos llegar al diagnóstico por otros métodos más adecuados ya que hemos tenido reactivaciones graves en casos de TBC genital subclínica. No obstante, nos ha conducido en varios casos a la sospecha de dicha entidad.

Las lesiones cervicales activas son contraindicaciones absolutas y deben ser curadas previamente por el peligro de diseminar el proceso infeccioso.

Sistemáticamente practicamos la HSG en los primeros días del ciclo siguientes a la menstruación, por dos razones fundamentales: a) con el objeto de no interferir con el paso del huevo a través de la trompa y b) porque el endometrio proliferativo es más adecuado ya que no interfiere con el paso del medio de contraste a través del ostium uterino, como pudiera suceder con el endometrio secretor. También proscribimos las relaciones sexuales en los días anteriores a la HSG y para la mejor interpretación de las placas procuramos la expulsión de los gases como tiempo previo, por medio de edemas. Los espasmos tubarios tratamos de evitarlos con el uso de antiespasmódicos. Metil - Bromuro de Hioscina.

Consideramos que la HSG es un procedimiento que requiere la colaboración del ginecólogo y radiólogo, para su mejor ejecución e interpre- 
tación, razón por la cual personalmente inyectamos el medio de contraste, previa aplicación del espéculo y la cánula. Usamos jeringa de 10 cc. y purgamos cuidadosamente el sistema, ya que las burbujas de aire interfieren con la correcta interpretación de las placas.

Como medio de contraste empleamos durante los primeros años los medios aceitosos (lipidol). Una de las dificultades que encontramos fue la imposibilidad de retener algunas pacientes que viven fuera de la ciudad durante 24 horas con el objeto de tomar radiografías de control (prueba de Cotte). Actualmente usamos un medio hidrosoluble, la Yodipamida viscosa al 70\% (Endografina)*, la cual nos proporciona placas con buen contraste y nos permite tomar controles a los 10 minutos; es menos irritante y de rápida absorción, lo cual evita la formación de granulomas en las trompas ocluídas.

Antes de inyectar el medio de contraste, retiramos el espéculo. Inyectamos $1 / 2$ cc. y bajo control radioscópico tomamos la primera placa de seriografía, con el objeto de investigar la cavidad uterina; continuamos inyectando suavemente el medio de contraste y se van tomando las restantes radiografías bajo control radioscópico, de manera que seguimos el medio de contraste a través del útero, las trompas y su paso al peritoneo cuando esto ocurre. Luego tomamos una placa panorámica AP $\mathrm{Y}$ otra oblicua. La prueba de control es tomada a los 10 minutos, después de haber mirado las radiografías anteriores, antes de que sean fijadas $y$ mientras tanto no retiramos la cánula hasta no haber constatado que las placas son satisfactorias. No usamos manómetro y el dolor manifestado

\footnotetext{
* Schering Alemana.
}

por la paciente nos sirve de guía para la presión que ejercemos sobre el émbolo de la jeringa. Durante el tiempo que dura la prueba estamos ejerciendo tracción moderada sobre el cérvix, con el fin de corregir las desviaciones uterinas.

El control radioscópico tiene también la finalidad de facilitarnos la observación de aquellos úteros de gran atonía o de gran cavidad, los cuales requieren la inyección de mayor cantidad de medio de contraste, ya que de otra manera podrían dar falsa imagen de oclusión por insuficiencia relativa del medio de contraste.

Con pacientes debidamente prepa radas, es raro que se presenten accidentes después de la HSG. Solamente hemos tenido dos complicaciones: una de ellas presentó exacerbación de un proceso pélvico y en la otra tuvimos una reactivación de una TBC subclínica con biopsia de endometrio negativa. No hemos tenido extravasaciones del medio de contraste.

Modernamente se recomienda el uso de la sonda de Folley para la HSG. Nosotros seguimos utilizando las cánulas de Hudgins y Kahn.

En nuestra casuística practicamos HSG a 91 pacientes; en 71 de ellas para tratar de precisar las alteraciones sugeridas en la PQ y en 20 como único medio para investigar el factor tubario uterino y cervical. Tabla 4 .

\section{Diagnóstico del FT por PQ y HSG}

Sumando los datos obtenidos con PQ y HSG diagnosticamos 152 casos de factor tubario (47.2 por ciento), en el grupo de 322 pacientes en estudio. Tabla 5. 
TABLA 4

PATOLOGIA TUBARIA Y HSG MANIZALES. 1945-1967

\begin{tabular}{lr} 
Estado de las Trompas & Número \\
\hline Oclusión bilateral a nivel de cuernos & 9 \\
Oclusión bilateral a nivel de fimbria & 8 \\
Hidrosalpinx bilateral & 3 \\
Hidrosalpinx unilateral & 3 \\
Oclusión en fimbria izquierda & 3 \\
Oclusión unilateral cuerno izquierdo & 11 \\
Oclusión unilateral cuerno derecho & 1 \\
Oclusión unilateral trompa izq. en istmo & 9 \\
Trompas adheridas & 4 \\
Trompas permeables & 40 \\
TOTAL & \\
\hline
\end{tabular}

TABLA 5

ESTADO DE LAS TROMPAS EN 322 PACIENTES INVESTIGADAS CON PQ Y HSG. MANIZALES. 1945-1967

\begin{tabular}{|c|c|c|}
\hline \multirow[b]{2}{*}{ Estado } & \multicolumn{2}{|c|}{ Pacientes } \\
\hline & $\mathbf{N}^{o}$ & $\%$ \\
\hline $\begin{array}{l}\text { Factor tubario } \\
\text { Normales }\end{array}$ & $\begin{array}{l}152 \\
170\end{array}$ & $\begin{array}{l}47,2 \\
52,8\end{array}$ \\
\hline TOTAL & 322 & 100,0 \\
\hline
\end{tabular}

\section{Factor Tubario asociado}

El factor tubario fue puro en 113 casos ( 74.3 por ciento); asociado en 39 casos (25.7 por ciento). Tabla 6. (Gráfica № 1).

\section{TABLA 6}

DISTRIBUCION DE 152 PACIENTES CON FAC TOR TUBARIO SEGUN ASOCIACION CON OTROS FACTORES. - MANIZALES 1945-1967

\begin{tabular}{lrrr}
\hline & \multicolumn{2}{c}{ Pacientes } \\
Factor & $\mathbf{N}^{\mathbf{9}}$ & $\%$ \\
\hline Puro & 113 & 74,3 \\
Asociado & Marital & 27 & 8,4 \\
". & Cervical & 6 & 1,8 \\
"' & Uterino & 4 & 1,2 \\
& Endocrino & 2 & 0,6 \\
\cline { 3 - 3 } TOTAL & 152 & 100,0 \\
\hline
\end{tabular}

\section{Etiología del Factor Tubario}

El estudio de los antecedentes de nuestro grupo que posiblemente intervinieron en la etiología del factor tubario puede observarse en la Tabla 7. (Gráfica № 2 ).

\section{TABLA 7}

\section{FACTORES ETIOLOGICOS DE ESTERILIDAD TUBARIA EN 152 PACIENTES MANIZALES. 1945-1967}

\begin{tabular}{lrr}
\hline & \multicolumn{2}{c}{ Pacientes } \\
Factor etiológico & $\mathbf{N}^{\mathbf{0}}$ & $\%$ \\
\hline Inflamación pélvica & 48 & 31,6 \\
Parto séptico & 21 & 13,8 \\
Apendicitis aguda & 11 & 7,2 \\
TBC genital & 8 & 5,2 \\
Miomatosis uterina & 8 & 5,2 \\
Aborto séptico & 6 & 4,0 \\
Endometriosis & 6 & 4,0 \\
Tumores de ovario & 3 & 2,0 \\
Desconocido & 41 & 27,0 \\
& 152 & 100,0 \\
\hline TOTAL & 152 & \\
\hline
\end{tabular}

Los casos de apendicitis aguda que existían en los antecedentes de 11 pacientes los presentamos en la Tabla 8 de acuerdo con el estado de las trompas a la $\mathrm{PQ}$. De estas pacientes 3 obtuvieron embarazo.

TABLA 8

\section{GRAFICA DE PQ EN 11 MUJERES OPERADAS PREVIAMENTE DE APENDICITIS AGUDA.}

MANIZALES. 1945-1967

\begin{tabular}{cccc}
\hline $\begin{array}{c}N^{0} \text { de } \\
\text { Pacientes }\end{array}$ & Normal & $\begin{array}{c}\text { Tipo de gráfica } \\
\text { Estenosis }\end{array}$ & Oclusión \\
\hline 11 & 0 & 5 & 6 \\
\hline
\end{tabular}

\section{Concordancia entre PQ y HSG}

La concordancia entre PQ y HSG no es absoluta; cada uno de los métodos presenta motivos de error, especialmente la $P Q$. 
Las fallas de técnica y el criterio de interpertación pueden determinar discordancia entre ambas pruebas; en tal caso se aceptan generalmente los hallazgos obtenidos por HSG, por reconocérsele mayor precisión.

Lelio y col. (15), del Servicio de Di Paola, presentan una concordancia del 70.7 por ciento y una discordancia del 29.3 por ciento entre la $P Q$ y la HSG. Atribuyen el hecho a fallas técnicas en algunas de las pruebas y a errores de interpretación.

Sobrero y col. (30), en un estudio de 500 mujeres estériles a las cuales practicaron $H S G$ y $P Q$, encontraron que la $H S G$ es más exacta que la $P Q$ en el estudio de la mujer estéril, ya que revela hechos precisos a todos los niveles, desde el cérvix hasta el útero y las trompas: pólipos, miomas, oclusión unilateral de trompas y otras condiciones que no habían sido sospechadas. Fueron concordantes ambos métodos en el 59.2 por ciento; en 271 para trompas permeables y en 25 para trompas no permeables. Fueron discordantes en 204 (40.8 por ciento). Hubo hallazgos similares y a menudo contradictorios. Cuando tuvo discrepancia entre los dos métodos prefirió los hallazgos de HSG por su objetividad.

En 71 pacientes practicamos ambas pruebas. Hubo concordancia para trompas permeables en 31 (43.7 por ciento); en 18 ( 17.0 por ciento) coincidió la estenosis con HSG anormal; en 9 ( 12.7 por ciento) hubo concordancia entre las dos pruebas para la oclusión. En resumen hubo concordancia para ambas pruebas en 52 pacientes (73.4 por ciento). Se presentó discordancia en 19 casos (26.6 por ciento). En la Tabla 9 presentamos nuestra concordancia.
TABLA 9

DISTRIBUCION DE 71 PACIENTES SEGUN LA CONCORDANCIA ENTRE PQ Y HSG. MANIZALES. 1945-1967

\begin{tabular}{lcc}
\hline \multirow{2}{*}{ Prueba } & \multicolumn{2}{c}{ Pacientes } \\
\hline Concordante & $N^{\mathbf{9}}$ & $\%$ \\
Discordante & 52 & 73,4 \\
\multicolumn{1}{c}{ TOTAL } & 19 & 26,0 \\
\cline { 2 - 3 } & 71 & $\overline{100,0}$ \\
\hline
\end{tabular}

\section{Hallazgos a la HSG}

En 39 HSG (42.8 por ciento) se encontró patología concomitante no sospechada en algunos casos. Tabla 10.

TABLA 10

PATOLOGIA CONCOMITANTE DESCUBIERTA

EN 91 HSG - MANIZALES. 1945-1967

\begin{tabular}{|c|c|}
\hline Hallazgos & Número \\
\hline Mioma intramural & 7 \\
\hline Mioma submucoso & 2 \\
\hline Pólipo cervical & 5 \\
\hline Pólipo uterino & 2 \\
\hline Incontinencia del cérvix & 6 \\
\hline Sinequias & 4 \\
\hline Utero arcuato & 6 \\
\hline Utero unicorne & 1 \\
\hline Utero bicorne & 2 \\
\hline Utero didelfo & 2 \\
\hline Utero duplex & 2 \\
\hline Sin patología concomitante & 52 \\
\hline TOTAL & 91 \\
\hline
\end{tabular}

\section{Factor Peritoneal (FP)}

El FP se confunde comúnmente con el FT y en realidad va ligado a él frecuentemente. El peritoneo desempeña una función importante en el fenómeno de la reproducción, por lo cual merece estudio especial.

Investigaciones cuidadosas llevadas a cabo por Murray (18), para determinar la fisiopatología del peritoneo pelviano y sistematizar los medios de 
diagnóstico, le han dado una individualidad ya aceptada.

El espacio tubo-ovárico debe conservar un peritoneo intacto para permitir el paso del óvulo hacia el oviducto y cualquier alteración de dicho espacio la dificulta (19). Las cicatrices de los estados inflamatorios, mucho más frecuentes de lo que se cree, son difíciles de reconocer y diagnosticar.

La TBC, la infección séptica y gonocóccica, las intervenciones quirúrgicas y las maniobras intrauterinas son causa muy conocida en la génesis del FP (20).

La infección apendicular también es causa de FP, por las adherencias que produce, particularmente cuando ocurre en la adolescencia con o sin apendicectomía. Puede pensarse que las adherencias perianexiales impedirán al óvulo alcanzar el ostium tubario antes de que sufra degeneración (20).

La endometriosis (20), tiene la particularidad de afectar el peritoneo pelviano, ya que cíclicamente se producen hemorragias focales muy irritantes, con gran capacidad para producir adherencias. Grandes procesos de endometriosis suelen evolucionar silenciosamnete, sin dismenorrea o con muy pocos síntomas que llamen la atención hacia esta entidad, inclusive en mujeres muy jóvenes. Con mayor razón pueden existir focos discretos de endometriosis a nivel del complejo tubo-ovárico, de difícil reconocimiento, pero causando suficientes alteraciones que impidan el embarazo. Rock (24), encontró endometriosis en el 30 por ciento de sus pacientes operadas, de las cuales la mitad parecían interferir con la función anexial.
Para el diagnóstico del FP deben tenerse en cuenta antecedentes como: infecciones genitales, apendicitis aguda, intervenciones quirúrgicas anteriores, matrimonio tardío (portadoras frecuentes de endometriosis), prácticas anticonceptivas, diferentes a los anovulatorios, porque se da campo para que los focos de endometriosis evolucionen.

Para el diagnóstico del FP se utilizan varios métodos: la $P Q$, la HSG, la Culdoscopia y Peritoneoscopia.

La PQ en la cual la omalgia se presenta tardíamente, debe hacernos pensar en el FP, ya que las adherencias dificultan el paso del gas a la cavidad peritoneal. En dos de nuestras pacientes en las cuales inicialmente se obtuvieron gráficas de permeabilidad, posteriormente la registraron de oclusión y en ellas se comprobó endometriosis externa a la laparotomía.

La HSG es complemento indispensable para el diagnóstico de FP. La prueba de control permite apreciar la distribución anormal del medio de contraste y la formación de bolsas.

La Culdoscopia ha sido usada por nosotros para investigar otro tipo de patología y no ha tenido lugar para el estudio de la permeabilidad tubaria, ni del FP, ya que tememos producir lesiones viscerales cuando se encuentran adherencias. La laparoto mía será la última y definitiva prueba que nos permitirá llevar a cabo el diagnóstico y tratamiento adecuado.

El FP ha sido sospechado por nosotros en un buen número de casos, pero la resistencia a la intervención por los resultados elatorios y escasos que nosotros mismos ponemos de presente a las pacientes, les impide someterse al tratamiento quirúrgico. 
Practicamos salpingolisis en 16 pacientes $y$ en otras fue complemento de intervenciones como miomectomías, resección cuneiforme y tumores de ovarios.

Las pacientes que presentan endometriosis merecen un comentario especial, pues la aparición de los anovulatorios ha mejorado notablemente el pronóstico de la fertilidad. Una de nuestras pacientes el caso número 106, estéril primaria de cuatro años, presentó accidente agudo por ruptura de endometrioma del ovario derecho; el bloqueo tubo-ovárico era bilateral y total. Se practicó resección parcial de focos y luego se instituyó terapia anovulatoria cíclicamente durante un año; durante el segundo año recibió terapia continuada (seudoembarazo). Al segundo mes de suspendida la terapia presentó embarazo, pero terminó en aborto a las 8 semanas. Después de cuatro meses de ocurrido el aborto se presentó nuevamente sintomatología atribuíble a recidiva, por lo cual se instituyó tratamiento ovulostático continuo, el cual recibe en la actualidad. Hemos operado pacientes después de tratamientos prolongados con anovulatorios, encontrando muy laxas las adherencias tubo-ováricas, pero muy firmes las correspondientes al sigmoide-útero.

También hemos incluído entre la salpingolisis las fimosis encontradas en una o ambas trompas, por considerar que la liberación de las franjas tubarias y su fijación no constituye operación plástica sino simplemente liberación de adherencias a nivel de las fimbrias. No hemos encontrado focos sospechosos de endometriosis en las fimosis operadas que pudieran explicar esta condición, ni antecedentes de inflamación pélvica en algunas de ellas.

De las 16 pacientes que se embarazaron, unas tenían gráficas de este- nosis y otras de oclusión. A la HSG, dos presentaron hidrosalpinx unilateral y otra paciente oclusión.

Sospechamos el FP en 11 pacientes basados en la omalgia tardía, los datos de HSG y en los antecedentes de apendicitis aguda. En el capítulo de Tratamiento daremos algunos detalles de estas intervenciones quirúrgicas.

\section{Duración de la esterilidad}

La duración de la esterilidad en el grupo en estudio osciló entre 1 y más de 20 años. Entre 5 y 10 años encontramos 72 pacientes de las cuales obtuvieron embarazo $20 \quad$ (27.8 por ciento); entre 10 y 15 años encontramos 32 de las cuales 4 (12.5 por ciento) obtuvieron embarazo; entre 15 y 20 años encontramos 10 pacientes con 3 embarazos ( 30.3 por ciento) con 20 y más años 2 pacientes y una obtuvo embarazo (50.0 por ciento). En la Tabla 11 presentamos la duración de la esterilidad agrupando las pacientes en lapsos de 1 año; las pacientes que tienen 10 años y más de esterilidad quedan incluídas en el grupo de 10 y más.

\section{TABLA 11}

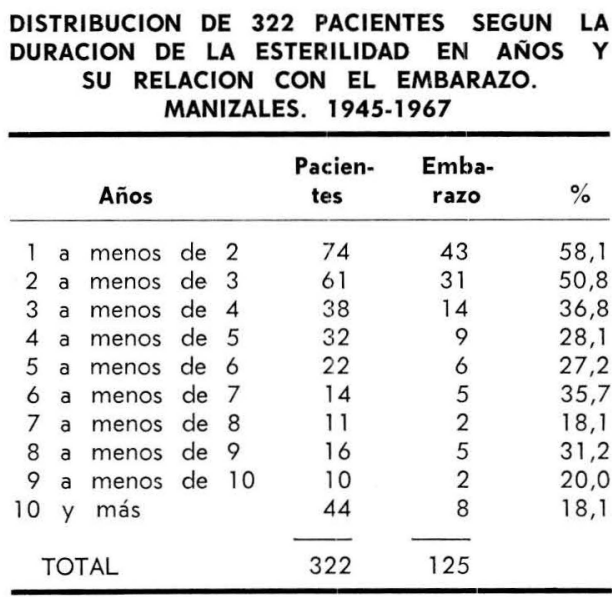




\section{Tiempo requerido} para la concepción

El valor terapéutico de $P Q$ es ampliamente reconocido. Rubin (26), estimó que el 26 por ciento de las pacientes presentan embarazo después de habérseles practicado la primera $P Q$ y si dicha prueba se repite varias veces, se embarazan el 31 por ciento de aquellas que presentan gráficas anormales con sospecha de estenosis. A. Stone y col. (34), encontraron un 34 por ciento de embarazos sobre 500 pacientes privadas, en los primeros tres meses de tratamiento. Sweyler (38) dice que el 36.0 por ciento de las pacientes se embarazaron en los primeros seis meses después de $P Q$; el 38.0 por ciento se embarazaron después de dilatación y legrado; el 35.0 por ciento después de HSG con medios hidrosolubles y el 42.0 por ciento cuando se usaron medios aceitosos.

Nosotros encontramos 12 embarazos (9.2 por ciento) después de la primera $P Q$ y anotamos que cinco de ellas lo obtuvieron en el mismo ciclo correspondiente a la prueba. Del segundo al tercer mes se embarazaron 30 ( 24.2 por ciento), pero en estos embarazos se presume que intervinieron otros procedimientos concomitantes, especialmente la dilatación y el legrado y tratamiento del factor cervical y marital.

\section{Edad en relación al embarazo}

En la Tabla 13 se presenta la relación edad-embarazo. Nótese que solo el 21 por ciento se embarazaron después de los 30 años.

\section{Factores y Procedimientos responsables de embarazo}

Presumimos que los factores responsables de embarazo en las 125
TABLA 12

\begin{tabular}{|c|c|c|}
\hline \multicolumn{3}{|c|}{$\begin{array}{l}\text { DISTRIBUCION DE LAS } 125 \text { PACIENTES SE } \\
\text { EL TIEMPO EN MESES TRANSCURRIDO DE } \\
\text { LA ADMISION HASTA EL EMBARAZO. } \\
\text { MANIZALES. } 1945-1967\end{array}$} \\
\hline \multirow[b]{2}{*}{ Tiempo } & \multicolumn{2}{|r|}{ Embarazos } \\
\hline & $\mathbf{N}^{\mathbf{o}}$ & $\%$ \\
\hline 1 a menos de 4 & 39 & 31,2 \\
\hline 4 a menos de 8 & 31 & 24,8 \\
\hline 8 a menos de 12 & 20 & 16,0 \\
\hline 12 a menos de 16 & 14 & 11,2 \\
\hline 16 a menos de 20 & 3 & 2,4 \\
\hline 20 a menos de 24 & 0 & 0,0 \\
\hline 24 y más & 18 & 14,4 \\
\hline TOTAL & 125 & 100,0 \\
\hline
\end{tabular}

Cabe observar que antes del primer año obtuvieron el embarazo el 72.0 por ciento.

TABLA 13

DISTRIBUCION DE LAS 322 PACIENTES SEGUN GRUPOS DE EDAD AL EMBARAZO.

MANIZALES. 1945-1967

\begin{tabular}{cccc}
\hline Edad & No $^{\mathbf{c}}$ & $\begin{array}{r}\text { Pacientes } \\
\text { Embarazo }\end{array}$ & $\%$ \\
\hline 20 & 15 & 9 & 60,0 \\
$20-24$ & 103 & 53 & 51,4 \\
$25-29$ & 102 & 37 & 36,3 \\
$30-34$ & 59 & 18 & 30,5 \\
$35-39$ & 40 & 7 & 20,0 \\
40 y más & 3 & 1 & 30,0 \\
TOTAL & -322 & 125 & \\
\hline
\end{tabular}

pacientes fueron los procedimientos que se emplearon en el diagnóstico y tratamiento de la esterilidad.

El FT se encontró como responsable en 45 pacientes ( 36.0 por ciento); el Factor Endocrino en 19 pacientes ( 15.2 por ciento) una de ellas recibió radioterapia estimulante de ovarios y seis obtuvieron el embarazo por tratamiento quirúrgico del Síndrome de Stein-Leventhal; con factor cervical 17 (13.6 por ciento); 
por procedimientos quirúrgicos 15 pacientes ( 12.0 por ciento); miomectomías, lisis de adherencias, tumores de ovario que afectaban las trompas, resección de focos de endometriosis; tratamiento de factores mixtos 16 (12.8 por ciento); por tratamiento del factor marital 10 (8.0 por ciento); por adopción 2 ( 1.0 por ciento); tratamiento de factor coital 1 (0.8 por ciento). Tabla 14 .

\section{TABLA 14}

DISTRIBUCION DE 125 PACIENTES SEGUN EL FACTOR Y EL TRATAMIENTO RESPONSABLES DEL EMBARAZO — MANIZALES. 1945-1967

\begin{tabular}{lrr}
\hline & \multicolumn{2}{c}{ Pacientes } \\
Factor & $\mathbf{N}^{\mathbf{9}}$ & $\%$ \\
\hline Cirugía (Tratamiento) & 15 & 12,0 \\
Tubario & 45 & 36,0 \\
Endocrino & 19 & 15,2 \\
Cervical & 17 & 13,6 \\
Múltiples & 16 & 12,8 \\
Marital & 10 & 8,0 \\
Adopción & 2 & 1,6 \\
Coital & 1 & 0,8 \\
\multicolumn{1}{c}{ TOTAL } & 125 & 100,0 \\
\hline & &
\end{tabular}

\section{Otros factores}

En la Tabla 15 se estudian otros factores de esterilidad en 322 mujeres tratadas.

TABLA 15

OTROS FACTORES DE ESTERILIDAD EN 322 MUJERES - MANIZALES 1945-1967

\begin{tabular}{lc}
\hline Factores & Número \\
\hline Marital & 33 \\
Cervical & 26 \\
Endocrino & 23 \\
Uterino & 14 \\
Endocrino-marital & 7 \\
Síquico & 5 \\
Coital & 2 \\
Desconocido & 53 \\
\hline
\end{tabular}

\section{Pronóstico del Factor Tubario}

En diversas estadísticas se considera que el 10 por ciento de los matrimonios son estériles.

Los estudios de la esterilidad femenina han impulsado la Ginecología en muchos aspectos tales como el endocrino, canalicular (cérvix, cavidad uterina, trompas y peritoneo) y sicosomático, conduciendo a la búsqueda de métodos de exploración funcional como la temperatura basal, dosificaciones hormonales, etc., lo cual se traduce en mejores pronósticos. El más amplio conocimiento de las funciones del endocérvix, el descubrimiento de la TBC genital subclínica con ocasión de biopsias y legrados de endometrio; de la fisiología de las trompas y su relación con entidades locales y de vecindad como apendicitis aguda, secuelas de intervenciones quirúrgicas, etc., también tienen influencia en el establecimiento del pronóstico de la esterilidad.

Según Siegler (27), el 26.6 por ciento de los casos tienen esterilidad absoluta, el 7.0 por ciento presentan causas ignoradas y el 70.4 por ciento presentan esterilidad relativa.

El pronóstico de la esterilidad por FT está en relación con la determinación de la permeabilidad de las trompas, además del FP tan ligado a ellas. Cuando se hace el diagnóstico por $P Q$ puede ocurrir que se obtenga una gráfica de oclusión existiendo normalidad orgánica, como ocurre con la presencia del espasmo. De otra manera pueden tomarse como permeables trompas con lesiones intrínsecas o extrínsecas las cuales perturban su fisiología, como cuando existen adherencias peritubarias $\circ \mathrm{hi}$ drosalpinx abiertos, que apenas se pueden sospechar con la PQ pero 
que la HSG puede poner en evidencia (9).

Marshak, citado por Figueroa Casas (9), presenta varios casos en los cuales a pesar de habérseles diagnosticado como oclusión a la $P Q$ y a la HSG, en la cirugía se comprobó que eran permeables. Debemos tener en cuenta estos márgenes de error al tomar decisiones quirúrgicas.

\section{Tratamiento del Factor Tubario}

Al terminar la evaluación de los diferentes factores que inciden sobre la fertilidad conyugal, es necesario recapitular y analizar cuidadosamente los datos consignados en la historia clínica con el fin de establecer un pronóstico y tratamiento adecuados.

En el tratamiento de la esterilidad, es frecuentemente difícil atribuir el embarazo a determinado método. Algunas pacientes se embarazan después de una o varias persuflaciones; otras lo hacen después de la HSG y solo puede presumirse que obtuvieron el embarazo después de la realización de algunas de estas pruebas. Como en cierto númreo de embarazos las pacientes han recibido tratamientos simultáneos, es difícil atribuir el resultado a determinado método.

El tratamiento del FT puede dividirse en: Médico, Fisioterápico y Quirúrgico.

\section{Tratamiento médico}

Debemos considerar en primer lugar la PQ como método terapéutico. Su repetición bien sea con entrada brusca del gas, presión sostenida o hiperpresión con el objeto de vencer una estenosis por acodadura, adherencias laxas o con el fin de vencer una oclusión a nivel de las fimbrias, mejoran frecuentemente las condiciones tubarias. Tabla 16.
TABLA 16

\begin{tabular}{|c|c|c|c|}
\hline \multirow[t]{3}{*}{$\begin{array}{l}\text { EFECTO } \\
\text { TES } Y\end{array}$} & $\begin{array}{l}\text { EN PQ EN } \\
\text { CON EL } \\
1945-1967\end{array}$ & \multicolumn{2}{|c|}{$\begin{array}{l}50 \text { PACIEN- } \\
\text { EMBARAZO. }\end{array}$} \\
\hline & & \multicolumn{2}{|c|}{ Embarazo } \\
\hline & $\begin{array}{c}\text { Pacine- } \\
\text { tes }\end{array}$ & $\begin{array}{l}\text { Nor- } \\
\text { mal }\end{array}$ & $\begin{array}{l}\text { Ectó- } \\
\text { pico }\end{array}$ \\
\hline Ocluídas a permeables & 11 & 4 & 0 \\
\hline Oclusión a estenosis & 16 & 1 & 2 \\
\hline Estenosis a permeables & 16 & 9 & 1 \\
\hline Estenosis a oclusión & 4 & 0 & 0 \\
\hline Permeables a oclusión & 3 & 1 & 0 \\
\hline & $\overline{50}$ & $\overline{15}$ & -3 \\
\hline TOTAL & 50 & 15 & 3 \\
\hline
\end{tabular}

Nótese que el 16,6 por ciento correspondió a embarazo ectópico.

\section{Histerosalpingografía como tratamiento del FT.}

Al aplicar la HSG en la investigación del FT con alguna frecuencia se presentan embarazos después de la prueba porque tiene efectos terapéuticos al mejorar la permeabilidad de las trompas. De las 91 pacientes a las cuales se les practicó HSG, 15 ( 16.4 por ciento) obtuvieron embarazo después de ella.

En otros medios se utiliza además la combinación de gas-aceite-gas preconizada por Weisman en 1950 y citado por Wilson (41), en el tratamiento del FT con buenos resultados.

El método consiste en pasar GO2 con la técnica $P Q$ y luego adaptar un mecanismo por HSG. Después de inyectar el medio de contraste (aceite) bajo control radioscópico, se inyecta nuevamente $\mathrm{CO} 2$ con el objeto de empujar el medio aceitoso y se obtienen las placas radiográficas. No ha sido empleado por nosotros.

Roland (25) opina que los métodos actuales de PQ y HSG están Ilenos de dificultades técnicas y que la correcta interpretación de la $P Q$ es 
difícil para muchos clínicos; finalmente que la HSG con medios aceitosos o hidrosolubles divide aún las opiniones. El uso de medio de contraste-gas evita la prueba de Cotte a las 24 horas y se puede usar inicialmente en el tratamiento de la oclusión tubaria. Tampoco ha sido usado por nosotros.

\section{Hidrotubación}

La hidrotubación consiste en la inyección continua de una solución terapéutica a través del útero y las trompas. Fue propuesta por Yagi (42). Si se acompaña de registro se llama Hidrotubación Quimográfica, ya que registra las curvas de presión. Tiene riesgos de infección por la posibilidad de arrastrar gérmenes del cérvix, de provocar hemorragias y algias pélvicas. Las soluciones empleadas y los beneficios terapéuticos varían según los autores.

Está indicada en el tratamiento de la Estenosis y de la Oclusión a nivel del pabellón, a razón de $3 \circ 4$ por ciclo, antes de la ovulación y por 2 ○ 3 ciclos. Se aconseja también en el post-operatorio de las Salpingostomías, después del tercer día de postoperatorio. Puede usarse aparatos especiales con manómetro como el preconizado por Palmer o simplemente una jeringa adaptada a la cánula uterina. La inyección debe practicarse lentamente y con suavidad; si al inyectar se encuentra resistencia, debe esperarse unos minutos, sin permitir que el líquido refluya en la jeringa; entonces se puede inyectar el resto sin resistencia. Terminada la inyección, se cierra la llave y se sostiene durante 10 minutos.

Un Hidrosalpinx puede retener el líquido y dar impresión de permeabilidad. En manos expertas es un auxiliar de $P Q$ y HSG pero no la subs- tituye. Tiene las mismas contraindicaciones de $P Q$ y HSG.

Las soluciones empleadas varían según el objetivo; puede usarse soluciones salinas, mezclas de antibióticos y corticoides, enzimas mucolíticas y procaína o xylocaína como algunos la prefieren.

Ascenzo Cabello (5) practicó 4.560 hidrotubaciones en 602 pacientes; tomó en cada paciente una HSG y 2 $P Q$ antes de la hidrotubación; la usó en combinación con ondas cortas y prednisona durante 60 días y las controló con HSG y/o 2 PQ. Utilizó succionato de Cloranfenicol 0.500 grs., dexametasona 4 mgs., hioluronidasa 250 unidades, diluídas en $20 \mathrm{cc}$. de suero fisiológico. Las pacientes que presentaban estenosis y oclusión tubaria comprobadas obtuvieron 96 embarazos ( 21.0 por ciento); fracasó en 152 (33.4 por ciento). No hubo resultados en pacientes en las cuales se había practicado previamente plastias tubarias. Las estenosis son generalmente distales o de factor peritoneal e impiden el embarazo como la oclusión verdadera.

En nuestra casuística hemos empleado la hidrotubación en 6 pacientes que presentaban oclusiones distales o estenosis, sin resultado. En el Departamento de Gineco-obstetricia del Hospital Universitario de Caldas estamos utilizándola y será motivo de comunicación especial cuando obtengamos un número suficiente de casos tratados en la consulta de esterilidad.

\section{Corticoides}

El uso de corticoides por vía oral por su acción antiflogística y resolutiva en el tratamiento de trompas estenosadas o con franca oclusión fue preconizado por Kurzrok y Streim 
(14) obteniendo permeabilización en 8 pacientes y 5 embarazos.

Ascenzo Cabello (6) trató con corticoides 10 pacientes con permeabilización del 50.0 por ciento de las trompas; no obtuvo embarazos.

Amaya León (1) de Bogotá, en 5 casos en los cuales usó Prednisona o Prednisolona combinados con diatermia, no obtuvo resultados positivos.

Nosotros usamos corticoides en 6 casos; en cinco no se modificó la gráfica de $\mathrm{PQ}$; en uno hubo mejoría de la gráfica y no se obtuvo embarazo. En 4 se asoció a vacunoterapia de choque; en 2 no hubo cambios en la gráfica de $P Q$; en 2 hubo mejoría y se presentaron 2 embarazos.

En 2 se asoció a ondas ultracortas; en 1 no se presentó modificación de la gráfica de $\mathrm{PQ}$; en 1 se observó mejoría y se obtuvo un embarazo.

\section{Fenilbutazona y Oxifen-butazona}

Con el objeto de evitar la formación de tejido fibroso como secuela de inflamaciones anteriores a nivel de las trompas, se ha usado la Fenilbutazona y Oxifenbutazona, drogas que tienen acción analgésica, antitérmica y antiflogística, fibrinolítica y acción sobre la permeabilidad capilar, semejante a la acción de los corticoides. Amorocho (2), trató 11 pacientes con Fenilbutazona y obtuvo 7 embarazos.

Nosotro susamos la Fenilbutazona y la Oxifenbutazona asialadamente en 4 pacientes; en 1 no se modificó la gráfica; en 3 hubo mejoría y se presentaron 2 embarazos. En 4 se asoció a ondas ultracortas y vacunoterapia de choque, obteniéndose 4 mejorías y 3 embarazos. En 1 paciente se asoció a ondas ultracortas con mejoría y embarazo. En 2 pacientes se asoció a antibióticos con 2 mejorías y 1 embarazo. En resumen se usó en 15 pacientes con mejoría en 12 ( 80.0 por ciento) y 5 embarazos (35.5 por ciento).

\section{Antibióticos y Vacunoterapia de Choque}

Usamos antibióticos y vacunoterapia de choque en aquellas pacientes con claros antecedentes de infección pélvica, en las cuales se había obtenido $P Q$ y $H S G$ anormales y en aquellas que tuvieron dolor pélvico y cierto grado de inflamación después de habérseles practicado estas pruebas, o modificación del leucograma y la eritrosedimentación.

Usamos preferencialmente la penicilina procaínica en caldo-vacuna como vehículo, si la paciente no es sensible a este antibiótico, en cuyo caso la substituímos por tetraciclina oral.

Este tipo de terapéutica fue usado por nosotros en 14 pacientes de los cuales en 5 no se presentó modificación de las gráficas de $P Q$; en 9 (64.3 por ciento) se presentó mejoría y hubo 4 embarazos (28.5 por ciento).

\section{Vacunoterapia de Choque como Tratamiento Unico}

La vacuna polivalente que usamos consta de un adyuvante (caldos envejecidos de estafilococo, estreptococo y polibacilo). El adyuvante es una substancia que agregada a un antígeno (gérmenes), aumenta sus propiedades antigénicas. La producción de anticuerpos aumenta por la inflamación que se produce localmente, en el sitio de la inyección del natígeno. Parece que al aumentar los fenómenos de sensibilización aumenta la respuesta de anticuerpos (8). 
El uso de vacunas se fundamenta en la respuesta inmunológica anamnésica (memoria) en un individuo que se supone previamente sensibilizado por haber sufrido infecciones. La reacción anamnésica se caracteriza por la aparición de títulos muy altos de anticuerpos que aparecen circulando en la sangre a los $2 \circ 3$ días después de la aplicación del antígeno, alcanzando un pico al séptimo día. El título de anticuerpos persiste más tiempo que el de la enfermedad primaria (8).

Fue usada la vacunoterapia de choque en 10 casos; en 8 de ellos no se presentó ningún cambio a la $P Q$; en 2 hubo evidencia de mejoría en la gráfica y se presentaron 2 embarazos.

\section{Antibioterapia como Tratamiento Unico}

Fue usado este tipo de tratamiento empleando penicilina procaínica, benzatínica o tetraciclina por vía oral en 5 pacientes; en una no se presentó cambios en la gráfica, en 4 hubo mejoría y se presentaron dos embarazos.

\section{Fisioterapia}

Usamos las ondas ultracortas por períodos de 2 meses como tiempo mínimo de tratamiento, a razón de 3 sesiones semanales, con media hora de duración cada una, con excepción de los días de la menstruación. Creemos que sigue siendo un buen coadyuvante en el tratamiento del FT en casos bien seleccionados.

Esta modalidad de tratamiento fue empleada por nosotros en 28 pacientes, unas veces asociada a otro tipo de terapia y otras como único tratamiento. Al parecer los resultados fueron excelentes cuando hubo asociación. Como única terapéutica fue usada en 8 pacientes, de las cuales
2 no presentaron cambios en las gráficas de $P Q ;$ en 6 se registró mejoría y se presentaron 3 embarazos.

En resumen, observamos buenos efectos terapéuticos cuando se empleó vacunoterapia asociada a antibióticos, fenilbutazona y ondas ultracortas; efectos aceptables cuando se usaron independientemente 0 en combinación con fenilbutazona. Esta última droga tuvo buen efecto cuando se usó sola o asociada a la vacuna y a la diatermia.

La terapia con ondas ultracortas tuvo buen efecto asociada a la vacuna; excelentes cuando se asoció a los antibióticos y bueno, asociado a la fenilbutazona.

Los corticoides asociados a la vacunoterapia produjeron resultados buenos y usados aisladamente no fueron satisfactorios. En la Tabla 17 se resumen los resultados obtenidos.

\section{Tratamiento Quirúrgico}

En 1897 Ries implantó al cuerno uterino la trompa restante de una resección y la llamó Metro-SalpingoAnastomosis. En 1903 Ferguson reportó salpingostomía e histerosalpingostomía con un embarazo (28).

En 1909 Turck reportó 8 casos de implantación con 2 embarazos a término. La reconstrucción de los oviductos es el procedimiento quirúrgico que da más pobres resultados debido a la inexperiencia de los cirujanos, técnica quirúrgica inadecuada y estudio insuficiente de las pacientes (37).

Muchas operaciones sobre las trompas se han practicado con ocasión de otra patología pélvica. Las publicaciones sobre este tipo de cirugía frenan y desalientan a los cirujanos para proponer más enfáticamente el tratamiento quirúrgico (37). 
TABLA 17

RESULTADOS OBTENIDOS EN 69 PACIENTES CON TRATAMIENTO MEDICO Y FISIOTERAPIA. - MANIZALES. 1945-1967

\begin{tabular}{|c|c|c|c|c|}
\hline Tipo de Tratamiento & Pacientes & Sin cambio de $P Q$ & Mejoría de $P Q$ & Embarazos \\
\hline Vacuna + Antibiótico & 14 & 5 & 9 & 4 \\
\hline Vacuna + Fenilbutazona + Diat. $^{*}$ & 4 & 0 & 4 & 3 \\
\hline Vacuna + Fenilbutazona & 5 & 3 & 2 & 2 \\
\hline Vacuna + Corticoides & 4 & 2 & 2 & 2 \\
\hline \multirow[t]{3}{*}{ Vacuna únicamente } & 10 & 8 & 2 & 2 \\
\hline & - & - & - & - \\
\hline & 37 & 18 & 19 & 13 \\
\hline Antibiótico + Fenilbutazona & 2 & 0 & 2 & 1 \\
\hline Antibiótico + Diatermia & 4 & 0 & 4 & 4 \\
\hline \multirow[t]{3}{*}{ Antibiótico únicamente } & 5 & 1 & 4 & 2 \\
\hline & - & - & - & - \\
\hline & 11 & 1 & 10 & 7 \\
\hline Fenilbutazona + Diatermia & 1 & 0 & 1 & 1 \\
\hline \multirow[t]{3}{*}{ Fenilbutazona únicamente } & 4 & 1 & 3 & 2 \\
\hline & - & - & - & - \\
\hline & 5 & 1 & 4 & 3 \\
\hline Corticoides + Diatermia & 2 & 1 & 1 & 1 \\
\hline \multirow{3}{*}{ Corticoides únicamente } & 6 & 5 & 1 & 0 \\
\hline & - & - & - & - \\
\hline & 8 & 6 & 2 & 1 \\
\hline Diatermia & 8 & 2 & 6 & 3 \\
\hline
\end{tabular}

* Ondas Ultracortas.

Debe tenerse en cuenta la buena fertilidad del esposo; el factor endocrino debe ser fundamentalmente establecido por Biopsia de Endometrio; la oclusión de las trompas debe ser demostrada lo mejor posible por tres $P Q$ consecutivas y transcurrido por lo menos un año y hasta dos de esterilidad. Debe tenerse en cuenta el espasmo persistente de las trompas como causa de error y se recomienda la Nitroglicerina sublingual $5 \mathrm{mi}$ nutos antes de la prueba. Se aconseja dar 40 mgs. de valerianato de estradiol más 250 mgs. de Caproato de Hidroxi-progesterona, 5 días antes y 5 días después de la cirugía, con el fin de producir seudoembarazo con lo cual se estimulará la regeneración de los tejidos pélvicos (37).

Según Tompkins (39), la multiplicidad de las técnicas empleadas hablan de lo poco satisfactorias y acon- seja levantar un registro nacional e internacional como para el Cáncer.

La implantación de la trompa, por poca que sea, con fimbria normal da las mejores posibilidades de éxito (3).

La fimbrioplastia da escasos resultados. El porvenir es el mismo con o sin polietileno (3).

El éxito de las anastomosis depende del tipo de lesión que ocasionó la oclusión. Los mejores éxitos se tienen cuando se trata de restablecer la permeabilidad de trompas previamente ligadas. Se puede emplear caperuza de plástico para proteger la fimbria y evitar adherencias, debiendo ser retirada tres meses después por segunda operación (4).

La oclusión a nivel del cuerno uterino es del 30 por ciento y a nivel 
del pabellón cerca del 70.0 por ciento. A nivel del pabellón se practican Salpingolisis, Salpingostomía, Salpingoestomatoplastia y Fimbroplastia. En la región del istmo se puede realizar Salpingectomía parcial con formación de Neopabellón o anastomosis término-terminal. Implantación tubo-uterina si el resto de la trompa está sana. Implantación del Ovario en el Cuerno. Opercaión de Estes (4).

\section{Salpingostomía}

En la Salpingostomía es difícil mantener permeable la abertura nueva, sin la formación de adherencias oclusivas. La primera fue practicada por Goullioud en 1899. Palmer (23), presentó 112 casos de Salpingostomía, y obtuvo 18 embarazos uterinos y 3 extrauterinos.

Buena cantidad de nuestras pacientes no permitieron la cirugía, al ser informadas sobre los escasos resultados de dichas intervenciones a nivel de las trompas. Por tal motivo nuestra casuística quirúrgica es corta en este tipo de cirugía. Se practicaron en total 23 intervenciones quirúrgicas sobre las trompas uterinas, las cuales pueden verse en la Tabla 18.

\section{TABLA 18}

DISTRIBUCION DE 23 MUJERES SEGUN EL TIPO DE CIRUGIA EN LAS TROMPAS. MANIZALES. 1945-1967

\begin{tabular}{lccc}
\hline & \multicolumn{3}{c}{ Embarazo } \\
Tipo de tratamiento & $\begin{array}{c}\text { Pacien- } \\
\text { tes }\end{array}$ & No & $\%$ \\
\hline $\begin{array}{l}\text { Salpingolisis } \\
\text { Salpingolisis con salpin- }\end{array}$ & 15 & 5 & 31,2 \\
gectomía parcial de trom- & & & \\
pa opuesta & 1 & 1 & 100,0 \\
Reimplantación de trompas & 2 & 0 & 0,0 \\
Salpingostomía & 2 & 0 & 0,0 \\
Salpingotomía & 2 & 1 & 50,0 \\
\multicolumn{1}{l}{ TOTAL } & - & - & - \\
\hline
\end{tabular}

\section{Salpingolisis}

La salpingolisis es la intervención que da mejores resutlados en el tratamiento de la esterilidad de causa tubaria. Morveh y col. (16) opinan que la lisis de las adherencias tubarias en 10 pacientes condujo a tres embarazos.

En nuestra casuística se practicaron 16 salpingolisis obteniéndose 5 embarazos y una salpingolisis con salpingectomía parcial de trompa opuesta, caso número 140, con esterilidad secundaria de 10 años y antecedentes de apendicitus aguda; tenía gráfica de estenosis y a la HSG hubo hidrosalpinx izquierdo. Al practicársele laparotomía se encontró que ambos ovarios se hallaban ocultos por adherencias; la trompa derecha estaba adherida y se practicó lisis de adherencias de la trompa y del ovario derecho; la trompa izquierda presentaba hidrosalpinx y se le practicó salpingectomía parcial. A los 6 meses se embarazó con parto normal. Nuevamente fue intervenida quirúrgicamente tres años más tarde, por embarazo ectópico en la trompa restante. Actuaron otros cirujanos.

El caso número 78, estéril primaria con $P Q$ normal y anexo izquierdo palpable presentaba hidrosalpinx derecho a la HSG. La laparotomía reveló trompa izquierda adherida y con fimosis; se trató el hidrosalpinx liberando las fimbrias y fijándolas con Catgut 4 ceros; la fimosis de la trompa izquierda se trató de la misma manera; se practicaron posteriormente varias $P Q$ con gráficas de permeabilidad; luego se embarazó y fue necesario practicarle cesárea. Actuaron otros cirujanos.

En las pacientes a quienes se les practicó salpingolisis había 6 casos 
de endometriosis en los cuales se practicó resección de focos y lisis de adherencias; se embarazaron 2. Cabe anotar que estas pacientes recibieron terapia anovulatoria, bien antes o después de la intervención. Algunas de estas pacientes fueron comentadas al hablar del FP. La endometriosis también se encontró asociada con tumores de ovario y miomatosis uterina.

El 20,0 por ciento de pacientes privadas que fueron sometidas a intervenciones ginecológicas presentaban endometriosis. En la consulta hospitalaria (caridad) tenemos alrededor de 11.0 por ciento de endometriosis en las pacientes operadas. Nosotros presentamos un informe al $\checkmark$ Congreso Nacional de Medicina de Bogotá.

\section{Reimplantación de Trompas}

Aunque en la literatura se consigna que la implantación de trompas da excelentes resultados siempre que la trompa esté sana (4), las dos reimplantaciones practicadas por nosotros, no tuvieron éxito.

\section{Salpingostomía}

En dos pacientes se practicó salpingostomía sin resultado.

\section{Salpingotomía}

La cirugía conservadora en el embarazo ectópico debe tenerse presente en primer lugar, cuando ha sido amputada previamente una de las trompas. Stromme (35), reporta 7 casos en los cuales practicó este procedimiento al hallar embarazos ectópicos no rotos, obteniendo 3 embarazos posteriores.

Hemos practicado salpingotomía a dos pacientes. El caso número 60 corresponde a una paciente estéril primaria de 22 meses y con gráficas de estenosis y antecedentes de apendicitis aguda operada años atrás. Presentó embarazo ectópico después de la PQ; a la laparotomía se encontró ovario izquierdo rudimentario y la trompa izquierda aparentemente sana pero muy delgada; en la trompa derecha cerca de la ampolla se encontró una tumoración de $3 \times 2 \mathrm{cms}$. correspondiendo a un aborto tubario retenido. Se practicó una incisión de 2 cms. sobre el dorso de la trompa, se extrajo el huevo retenido, se limpió suavemente el endosalpinx y se suturó la herida con Catgut 4 ceros en sentido transversal. Se practicaron $5 \mathrm{PQ}$ posteriormente se tomó HSG que aparecía normal y al mes siguiente se embarazó. Actualmente tiene 4 hijos.

El caso número 226 correspondió a una mujer estéril primaria de 4 años con gráficas de $P Q$ primero de estenosis y luego de oclusión. Como además se sospechaba endometriosis se instituyó tratamiento con anovulatorios durante 8 meses, presentándose embarazo ectópico a los 2 meses de suspendido el tratamiento. A la intervención se encontró la trompa derecha tortuosa, dura, al parecer con salpingitis nudosa; en el ovario izquierdo existía una tumoración quística de $6 \times 6$, la cual fué extirpada y no pudo ser clasificada por el estudio histopatológico; en la trompa izquierda y cerca de la ampolla se encontró un embarazo retenido (aborto tubario) practicándose incisión sobre el dorso de la trompa de unos $2 \mathrm{cms}$., se extrajo el huevo y se suturó transversalmente. Este caso fué operado recientemente, por lo cual no conocemos los resultados.

En algunas paceintes con RVF uterina practicamos suspensión y corrección generalmente con la técnica 
de Lanzko y a veces complementada con Pestalozza.

\section{Otra cirugía en relación con la esterilidad por FT}

No es infrecuente que lesiones orgánicas etxratubarias incidan sobre la fertilidad (miomas, tumores ováricos), o la coincidencia con Síndrome de Stein-Leventhal, por lo cual se presenta embarazo después de la intervención quirúrgica.

\section{Mioma y esterilidad}

El mioma uterino es un tumor que interfiere frecuentemente con la fertilidad por varios mecanismos; bien sea obstruyendo el orificio interno del cérvix, dificultando la anidación del huevo, o provocando abortos y partos prematuros.

Desde el punto de vista tubario puede comprimir la zona de los cuernos uterinos, o las trompas mismas, favoreciendo la aparición de endometriosis al nivel de ella. Contribuye a perturbar el buen funcionamiento del oviducto, distorsionándolo y alejando el ovario cuando el tumor es de gran tamaño.

El 20.0 p r ciento de las mujeres por debajo de los 50 años presentan miomatosis uterina. La mayoría de ellos no dificultan la concepción, pero pueden ser estériles el 40.0 por ciento de las mujeres con miomas demostrables clínicamente. ( $\mathrm{H}$. Thomas (40). Además, el mioma coexiste en alto grado con pólipos e hiperplasia del endometrio (13), y su extirpación en mujeres estériles da el 50.0 por ciento de éxitos. Stevenson (33), da el 50.0 por ciento de embarazos en mujeres que no habían concebido antes de la operación; excluye a las que presentaban infecciones previas, factor marital o usaban anticonceptivos.
Finn (10), relata en su estadística que el 48.5 por ciento de miomectomías en mujeres deseosas de embarazo lo obtuvieron.

Nosotros practicamos miomectomías en 9 pacientes, con miomas de fondo 7 en 2 interesaba la cavidad uterina, obteniéndose 4 embarazos normales ( 44.4 por ciento). En tres había gráfica de estenosis y en dos de oclusión. Uno de los casos con fimosis de trompas y no se embarazó; otro estaba asociado a endometriosis.

\section{Tumores de ovario y esterilidad}

En nuestra corta casuística operamos 7 pacientes con tumores de ovario y se embarazaron 3; uno de ellos era un Arrenoblastoma y se embarazó posteriormente (con signos de virilización); otro caso era un quiste seudomucinoso asociado a un Stein-Leventhal y tuvo embarazo posteriormente. Otro caso se asoció a endometriosis externa y no se obtuvo embarazo. Otro se asoció a TBC. En otro al extirpar le tumor se practicó lisis de adherencias tubarias, sin embarazo posterior.

\section{Stein-Leventhal}

En 11 mujeres se practicó resección uneiforme de ovarios y se obtuvieron 6 embarazos; en uno de ellos estaba asociado a fimosis de las trompas.

\section{Sinequias uterinas 0 Síndrome de Ashermann}

En una paciente se practicó desprendimiento de sinequias intrauterinas sin producirse embarazo.

\section{Hiímen Fibroso}

En un caso con 7 años de esterilidad primaria y relaciones sexuales incompletas se practicó incisión del hímen con embarazo ulterior. 


\section{Tuberculosis y Fertilidad}

No es fácil conocer la incidencia de tuberculosis genital femenina; pero con el funcionamiento de los consultorios especializados en esterilidad en donde se practican rutinariamente biopsias y legrados con fines diagnósticos, se han podido obtener índices regionales; en Inglaterra por ejemplo, el 5,2 por ciento de las mujeres que concurren a los consultorios especializados presentan localización genital de la TBC.

En un estudio de 64 casos de TBC genital presentado por nosotros al $\mathrm{V}$ Congreso Nacional de la Especialidad, registramos 29 casos (45.3 por ciento) con localización endometrial y 33 casos ( 51.6 por ciento) de localización tubaria; en 2 casos (3.1 vor ciento) el diagnóstico se hizo por cultivo exclusivamente. La coexistencia de la TBC en las trompas $y$ en el endometrio solamente la hemos podido demostrar en el 55.0 por ciento. Presentaban esterilidad primaria 27 pacientes (42.2 por ciento) y esterilidad secundaria 9 ( 14.1 por ciento). En esa época (1956-1963) se consignó el 6.7 por ciento de las pacientes de la consulta hospitalaria de caridad que presentaban TBC genital y el 1.8 por ciento en las pacientes atendidas en la consulta privada. Esto nos da una idea de la importancia del factor socioeconómico (7).

Murray (21), reportó el 41.66 por ciento de pacientes que presentaban gráfica de oclusión bilateral a la $P Q$ y 58.3 por ciento con gráfica de permeabilidad con defecto de gráfica. Halbrecht (12), opina que la TBC es causa frecuente de esterilidad primaria y la infección post-parto y postaborto lo es en la esterilidad secundaria. La TBC lesiona el endosalpinx desde las fimbrias al istmo estre- chando progresivamente la luz tubaria. Sharman (12), citado por Halbrecht, fue quien primero llamó la atención en 1943 sobre el papel de la TBC en la etiología de la oclusión tubaria en la esterilidad primaria. Cada día se reportan más embarazos a término después de tratamientos adecuados, pero produce también predisposición al embarazo ectópico.

Teniendo en cuenta que la TBC genital se localiza en el 100.0 por ciento de los casos en las trompas lógico es suponer que desempeña un papel importante en la esterilidad por factor tubario. No siempre es posible llegar al diagnóstico de esta entidad con los métodos actuales. Wood (43), sobre 500 casos de TBC genital tubaria encontró localización endometrial en el 85.0 por ciento. Nosotros, por falta de elementos diagnósticos no hemos sobrepasado el 55.0 por ciento. Este hecho explica el que muchas mujeres sean intervenidas quirúrgicamente con biopsias de endometrio negativas y que la TBC genital sea un hallazgo quirúrgico en muchos casos.

En el presente trabajo reportamos 8 casos con TBC genital; en 7 la esterilidad era primaria y secundaria en la otra. La PQ proporcionó gráficas de estenosis en 3 casos ( 37.5 por ciento); de oclusión en 5 (72.5 por ciento).

En uno de los casos, paciente estéril primaria de 2 años, se sospechó la TBC genital por la existencia de masas anexiales; varias biopsias fueron negativas. Había sido tratada por TBC pulmonar y después de completar un año de tratamiento el cultivo de endometrio fue positivo para B.K. Recibió tratamiento tuberculostático por un año más obteniéndose al cabo de este tiempo gráficas que correspondían unas a estenosis y otras 
a oclusión. Una HSG fue completamente normal; a los 8 meses fue operada por aborto tubario izquierdo. Después de 3 años no ha vuelto a presentar embarazo.

Otro caso fue interveniod quirúrgicamente con diagnóstico de tumor de ovario encontrándose un cuadro de TBC, un endometrioma de ovario derecho y numerosas adherencias.

Otra paciente que anteriormente había presentado una TBC ganglionar en el cuello, después de practicársele una HSG presentó una complicación posterior; una biopsia de endometrio previa era negativa; fue necesario intervenirla quirúrgicamente con el fin de extirpar las masas anexiales que se habían infectado secundariamente con motivo de la HSG.

En dos pacientes más la HSG reveló hidrosalpinx bilateral en una $\mathrm{e}$ hidrosalpinx unilateral en la otra que, por otra parte, había presentado gráfica de estenosis a la PQ.

Las gráficas de $P Q$ que inicialmente denotan permeabilidad 0 estenosis y luego oclusión, las consideramos sospechosas de TBC genital o endometriosis.

\section{Embarazo ectópico}

La incidencia de embarazo ectópico es mayor en mujeres estériles que en las normales. Después de haber sido sometidas a tratamiento aumenta su frecuencia (11). La incidencia en la comunidad es del 1 por ciento $y$ de 2.4 por ciento en las mujeres estériles. Las posibilidades de embarazo ectópico son entonces el doble en estas últimas cuando están sometidas a tratamiento. Cuando se diagnostica embarazo ectópico la intervención debe ser precoz; debe hacerse una limpieza meticulosa de coágulos en la cavidad pélvica con solución salina, por la gran capacidad de formar adherencias que tiene la sangre. Si la trompa opuesta está en malas condiciones debe conservarse la trompa residual. Está indicado el uso de antibióticos en el post-operatorio a título profiláctico y debe iniciarse la $P Q$ en pocas semanas (11).

En nuestra casuística se presentaron 5 embarazos ectópicos (4.0 por ciento); en un caso la gráfica era de permeabilidad; en 2 de estenosis $y$ en 2 de oclusión.

\section{Abortos}

La incidencia del aborto se presenta por igual en mujeres fértiles 0 estériles.

Por un interés muy explicable hemos seguido el curso de los embarazos obtenidos con motivo de la investigación y el tratamiento del factor tubario en las 125 pacientes, encontrando 20 abortos (16.1 por ciento). Si sumamos los embarazos ectópicos a los abortos deducimos que en nuestra casuística se malograron 25 embarazos (20.1 por ciento) sobre 125 obtenidos con motivo de la investigación y tratamiento de 322 mujeres estériles.

\section{Sumario}

1. Se investiga el Factor Tubario en 322 pacientes de la consulta de esterilidad Privada. El Factor Tubario se estudia por Persuflación Quimográfica en 302 pacientes y por Histerosalpingografía 91; exclusivamente po reste último método en 20.

2. De las 322 pacientes 204 (63.3 por ciento) presentan esterilidad primaria; 116 (36.7 por ciento) presentan esterilidad secundaria. 
3. Se hace una breve descripción de las técnicas de Persuflación Quimográfica e Histerosalpingografía, con sus posibles fallas de técnica e interpretación.

4. Mediante las técnicas de Persuflación Quimográfica e Histerosalpingografía se diagnostica Factor Tubario en 152 pacientes (47.2 por ciento) de 322 en estudio.

5. Se hace una enumeración de factores asociados al Factor Tubario (marital, cervical, uterino, endocrino).

6. Se analiza la etiología del Factor Tubario en 152 pacientes.

7. Se estudia la concordancia entre Persuflación Quimográfica e Histerosalpingografía.

8. Se hace un comentario sobre la patología hallada por Histerosalpingografía.

9. Se estudia el factor peritoneal, sus causas, diagnóstico, tratamiento y su relación con el factor tubario.

10. Se analizan 125 embarazos y los posibles factores y métodos terapéuticos que intervienen en su producción.

11. Se estudia la edad y su relación con el tiempo de esterilidad y embarazo.

12. Se enumeran otros factores de esterilidad encontrados en 322 pacientes.

13. Se hace un somero análisis de las distintas formas de tratamiento de la esterilidad: médico, fisioterápico y quirúrgico.

14. Se presenta una corta experiencia en el tratamiento del Factor Tubario con vacunoterapia de cho- que, antibióticos, Fenilbutazona, corticoides y ondas ultracortas.

15. Se analizan los embarazos ectópicos y abortos en 125 pacientes.

16. Se estudia la relación de la TBC genital con el Factor Tubario.

17. Se analizan 11 casos de pacientes que presentan antecedente de apendicitis aguda y su relación con el Factor Tubario.

\section{BIBLIOGRAFIA}

1 AMAYA LEON, H.: Cortisona en el Tratamiento de Esterilidad Femenina por Obstrucción Tubaria. Revista Colombiana de Obstetricia y Ginecología. IX - 570. 1958.

2 AMOROCHO, J.: Nuevas Observaciones sobre el uso de la Fenil-Butazona en las Obstrucciones Tubarias. Revista Colombiana de Obstetricia y Ginecología, XI. 414. 1960.

3 ARENAS, N., BETTINOTTI, A. E., MURRAY, E. G.: Esterilidad conyugal. Editorial $\mathrm{Bi}-$ bliográfica Argentina. Pág. 162. 1956.

4 Esterilidad Conyugal. Editorial Bibliográfica Argentina. 448-450-452 pp. 1956.

5 ASCENZO CABELLO, J.: Hidrotubaciones Histerotubáricas en el tratamiento de la Oclusión Distal Tubárica. Tribuna Médica. Bogotá. No 281. VI. 24-25. 1967.

6 Nuestra experiencia con la Cortisona en las Obstrucciones Tubarias. Second World Congress. I 983. 1956.

7 BOTERO PELAEZ, B., MONTES SAENZ J., ACEBEDO FERRER O., GIRALDO A. J.: TBC genital femenina. Revista Colombiana de Obstetricia y Ginecología. XV. 137-138139. 1964.

8 CRIEP, LEO H.: Fundamentals of Inmunology. Grune and Straton. New York and London. Pág. 9. 1962.

9 FIGUEROA CASAS, P.: Pronóstico de la Esterilidad. Obstetricia y Ginecología Latinoamericana. XVII. 326. 1959.

10 FINN, W. F. and MULLER, P. F.: Abdominal Myomectomy: Special Reference to Subsequent Pregnancy and to the Reappearance of Fibromyomas of the Uterus. American Journal of Obstetrics and Gynecology. LX. 112. 1950.

11 GRANT, A.: The Effect of Ectopic Pregnancy on Fertility. Report of a Study of 
353 Cases. Clinical Obstetrics and Gynecology. V. 864. 1962.

12 HALBRECHT, I.: Latent Genital Tuberculosis. International Journal of Fertility. I. 368. 1956.

13 INGERSOL, F. M.: Fertility Following Myomectomy. Fertility and Sterility. XIV. 598. 1963.

14 KURZROK, L. and STREIM, E.: Cortogen Treatment for Sterility. Due to Nonplatent Tubes. Fertility and Sterility. V. 515. 1954.

15 LELIO, M. y col.: Concordancia entre PQ y HSG. Obstetricia y Ginecología Latinoamericana. XVII. 152. 1959.

16 MROUEH, and GLASS, R. H.: Tubal Plastic Surgery. Fertility and Sterility. XVIII. 81. 1967.

17 MURRAY, E. G. y SIERRA, D.: Trastornos del Funcionamiento Tubario como Causa Determinada de Esterilidad. Revista de la Facultad de Medicina. Bogotá. XI. 351. 1942

18 MURRAY, E. G.: Peritoneal Factor in Sterility. Clinical Obstetrics and Gynecology. V. 837.1962.

19 Pathology of Tubal Occlusion. First World Congress on Fertility and Sterility. II. 113. 1953.

20 MURRAY, E. G.: Peritoneal Factor in Sterility. Clinical Obstetrics and Gynecology. V. 837.1962.

21 Esterilidad por Tuberculosis Genital Femenina. Obstetricia y Ginecología Latinoamericana. VIII. 228. 1950.

22 PALMER, R.: Las Exploraciones Funcionales Ginecológicas. Toray Masson. Pág. 144. 1966.

23 Résultats de la Chirurgie dans Deux Gents Cas D'Obturation Tubale. First World Congress on Fertility. II. 181. 1953.

24 ROCK, J.: Surgery for Female Infertility. Fertility and Sterility. VIII. 516. 1957.

25 ROLAND, M.: Hysterosalpingography and Carbon Dioxide Insuflation as a Combined Therapeutic Procedure. Fertility and Sterility. XIV. 29. 1963.

26 RUBIN, I. C.: Value in the Treatment of Tubal Obstruction to Ovular Migration. Fertility and Sterility. V. 321. 1954.

27 SIEGLER, S. L. : Fertility in Women. Ed. Lippyncott. Pág. 13. 1944.
28 SIEGLER, A. M.: Tuboplasty. Clinics Obstetrics and Gynecology. VIII. 822. 1962.

29 SIMONS, F.: The Diagnosis and Treatment of the Infertile Couple. Reprint the Southern Medical Journal. XXXXVI. 34. 35. 36. January. 1953.

30 SOBRERO, A. J., SILBERMAN, C. J., POST A., CINER, L.: Tubal Insufflation and Hysterosalpingography. Obstetrics and Gynecology. XVIII. 92. 1961.

31 STABILE, A.: Métodos de Exploración de la Función Tubaria. Archivos Uruguayos de Medicina, Cirugía y Especialidades. XL. 15. 1952 .

32 STALLOWORTHY, J. A.: The Prbolems of Functional Aspectis of Uterine and Tubal Occlusion. Second World Congress on Fertility and Sterility. I. 831. 1956.

33 STEVENSON, C. S.: Myomectomy for Improvement of Fertility. Fertility and Sterility. XV. 367. 1964.

34 STONE, A. and WARD, M. E. : Factors Responsible for Pregnancy in 500 Infertility Cases. Fertility and Sterility. VII. 4. 1956.

35 STROMME, W. B., Mc KELVEY, J. L. and DOUGLAS ADKINS, C.: Conservative Surgery for Ectopic Pregnancy. Obstetrics and Ginecology. XIX. 295. 1962.

36 SWEENEF III. W. J.: Pirpalls in Present Day Methods of Evaluating Tubal Function: I. Tubal Insufflation. Fertility and Sterility. XXIII. 115. 1962.

37 SWEENEY III. W. J. and GEPFER, T. R. : The Fallopian Tube. Clinical Obstetrics and Gynecology. VIII. 41. 1945.

38 SWEYER, G. I. M. and FOURACRE BARNS, H. H.: The Incidence of Conception Following Tubal Patency Tests Compared with that Following Endometrial Biopsy. International Journal of Fertility. II. 302. 1957.

39 TOPKINS, P. T.: The Incidence of Pregnancy Following Tuboplastic Surgery. International Journal of Fertility. III. 183. 1958.

40 THOMAS, H. H.: The Uterus. Clinical Obstetrics and Gynecology. VIII. 52. 1965.

41 WILSON, R. B. and MASSEE, J. S. : Sequential Gas-Oil-Gas Procedure in the Therapy of Infertility. Fertility and Sterility. XIII. 367. 1962.

42 YAGI: Hidrotubación. Fertility and Sterility. VI. 550. 1955.

43 WOOD, J., Y. ELGUETA, H.: Genital Tuberculosis and Sterility. Int. Jour. Fertility. III. 367. 1958. 